ORIGINAL ARTICLE

\title{
Improving golf performance with a warm up conditioning programme
}

\author{
A J Fradkin, C A Sherman, C F Finch
}

Br J Sports Med 2004;38:762-765. doi: 10.1136/bjsm.2003.009399

See end of article for authors' affiliations .....................

Correspondence to: Dr A J Fradkin, Monash University, Epidemiology and Preventive Medicine, Alfred Hospital, Melbourne 3004, Australia;

andrea.fradkin@ med.monash.edu.au

Accepted

25 November 2003

\begin{abstract}
Objectives: To determine whether a golf specific warm up programme (both immediately prior to play and after performing it five times a week for 5 weeks) improved performance in 10 male golfers compared with 10 controls matched for age, sex, and handicap.

Methods: Twenty male golfers were matched for age ( \pm 2 years) and handicap ( \pm 1 stroke). Club head speed was assessed by two dimensional video analysis in a laboratory setting. In week 1, all golfers performed 10 strokes. In weeks 2 and 7, the controls underwent the same procedure as in week 1. The exercise group performed the golf specific warm up followed by their 10 strokes. Between weeks 2 and 7 , the exercise group performed the specially designed warm up five times a week for 5 weeks.

Results: The mean club head speeds of the exercise group improved at each testing week. Between weeks 1 and 2, golfers in the exercise group improved their club head speed on average by $3-6 \mathrm{~m} / \mathrm{s}(12.8 \%)$, and between weeks 1 and 7, they increased their club head speeds by $7-10 \mathrm{~m} / \mathrm{s}(24.0 \%)$. With the exception of one golfer whose club head speed varied by $1.7 \mathrm{~m} / \mathrm{s}$, the mean club head speeds of the golfers in the control group hardly varied over the testing period (range: $0.3-0.8 \mathrm{~m} / \mathrm{s}$ ). A significant difference $(p=0.029)$ was found between the mean club head speeds of the exercise and control groups over the duration of the study, and a significant interaction over time $(p<0.001)$ was also found.

Conclusions: This study has shown that golfers' performances will be significantly improved by undertaking a golf specific warm up programme compared with not performing the warm up.
\end{abstract}

$\mathrm{T}$ he term warm up is defined as a period of preparatory exercise in order to enhance subsequent competition or training performance. ${ }^{1}$ The purpose of a warm up is to prepare the body both physiologically and psychologically, while at the same time reducing the risk of injury. ${ }^{2}$

A number of studies were conducted in the 1950s-1970s to investigate the effects of warming up. ${ }^{3-7}$ Approximately $60 \%$ of these studies found some type of warm up to be superior to no warm up, approximately $11 \%$ found no warm up to be superior, and approximately $29 \%$ found no significant difference between different types of warm up and no warm up. ${ }^{8}$

In interpreting these studies, however, an important consideration is that most had major faults. Often there was no control group, the research was based on a poor study design, or the participants used were inappropriate. ${ }^{34679}$ Nevertheless, the weight of evidence suggests that warming up prior to play will improve performance compared with doing nothing at all.

Warming up is widely promoted as an important performance enhancing and injury prevention measure for both amateur and professional golfers. ${ }^{10}$ Even though this has not been formally evaluated in golfers, numerous recommendations for the most appropriate warm up routine have been presented in the golfing literature. ${ }^{11}$ The differences in the suggested warm up times range from 4 to 45 minutes, and the warm up routines suggested also differ considerably. To date, there have been no scientifically sound studies determining whether warming up prior to playing golf reduces injury risk or improves performance.

Four studies have investigated the effect of conditioning programmes on performance in golfers; ${ }^{12-15}$ however, these all have limitations in their basic design. The main fault, other than not having a control group, is that none of the studies validated (or even explained) the tests and outcome measures used. This makes it difficult to determine whether the exercise programme actually improved golf performance, rather than just showing general strength and flexibility improvements. The purpose of this study was to undertake a controlled study to investigate the effects of a golf specific warm up and conditioning programme on club head speeds in amateur adult male golfers.

\section{METHODS}

\section{Participants}

Twenty male golfers participated in this study. The golfers ranged in age from 23 to 64 years (mean 39.6) and had a range of handicaps from 12 to 27 (mean 19.8). All golfers were matched according to age $( \pm 2$ years) and handicap $( \pm 1$ stroke) (table 1$)$. After the matched pairs were identified, participants were randomly placed in either a control or exercise group. Informed written consent was obtained from each participant prior to data collection, and each participant was debriefed following completion of the study. The Deakin University human research and ethics committee approved this study.

\section{Warm up and conditioning programme}

A warm up routine and conditioning programme specifically for golf was developed by analysing golf articles and determining the most commonly recommended stretches. ${ }^{16-28}$ Information about the major muscles used during a golf swing using electromyography was also used to ensure that these muscles were covered by the stretching routine. ${ }^{29-36}$ The warm up was checked by a sports medicine doctor and a golf physiotherapist to ensure all exercises were safe and effective.

The warm up programme consisted of three parts. Firstly, there were four exercises of approximately 15 seconds each, with the purpose of increasing body temperature. These exercises were performed briskly to get the body moving and included exercises such as windmills and trunk twists. Secondly, there was a series of nine static stretches, which 


\begin{tabular}{|c|c|c|c|c|c|c|c|c|c|c|}
\hline Matched pair & 1 & 2 & 3 & 4 & 5 & 6 & 7 & 8 & 9 & 10 \\
\hline \multicolumn{11}{|l|}{ Age } \\
\hline Exercise & 23 & 40 & 46 & 50 & 56 & 26 & 28 & 27 & 61 & 63 \\
\hline Control & 25 & 41 & 47 & 52 & 56 & 25 & 29 & 28 & 61 & 64 \\
\hline \multicolumn{11}{|l|}{ Handicap } \\
\hline Exercise & 12 & 14 & 16 & 16 & 18 & 19 & 25 & 24 & 27 & 27 \\
\hline Control & 13 & 14 & 17 & 17 & 17 & 18 & 24 & 25 & 27 & 27 \\
\hline
\end{tabular}

focused on stretching the major golf muscles: three for the shoulder, one for the lateral trunk/lower torso area, one for the hamstrings/lower back, one for the chest, two for the wrist, and one for the forearm. Each stretch was required to be performed twice on each side of the body and was held in its final position for at least 5 seconds. Finally, 30 seconds of air swings with a golf club were performed, with a gradual increase in range of motion and vigour.

\section{Apparatus}

The experimental arrangement used in the indoor laboratory was as follows. The golf mat was placed $2.2 \mathrm{~m}$ from the rear wall and $2.2 \mathrm{~m}$ from the side wall. The net was set up $1.95 \mathrm{~m}$ from the golf mat so as not to interfere with the swing, but to catch the ball and immediately drop it to the floor, so that the ball would roll back towards the golfer rather than being flung straight back at them.

A stationary high speed camera (Redlake MotionScope PCI 500S) was set up directly in line with the golf mat, and was operated at a frequency of $250 \mathrm{~Hz}$ ( 125 frames per second) and a shutter speed of $1 / 500 \mathrm{~s}$. Prior to each session, the camera was re-calibrated to ensure that reference points were available for digitising. The calibration pole was placed at two reference points on the edge of the filming area to supply reference points for filming.

A pre-trigger function was used to enable the collection of video footage to be triggered at the end of a movement, such as at the end of the follow through phase of the golfers' swing. This ensured that the video images saved also included the video footage prior to the trigger - that is, the downswing and ball impact.

Videotape footage of the golfers' swings was analysed using the software Video Expert 2. Exact measurements and dimensions of the test area needed to be calculated before any analyses could be performed. The Video Expert 2 program calculated the club head speed upon impact by taking the speed of the club head in the frame prior to ball contact, upon ball contact, and in the frame immediately after ball contact, and then reported on the exact club head speed upon impact. The point used for digitising was the point on the club where the shaft joined the club head. The Video Expert 2 program allowed for frame by frame movement, so that the exact reference point was located during digitising.

\section{Experimental design}

A 5 week testing schedule was chosen because other studies have shown that changes in performance can occur over that time, ${ }^{514}$ and, for compliance reasons, the study was chosen to be as short as possible. Table 2 shows the testing schedule with intervention 1 corresponding to performing the warm up immediately prior to performance and intervention 2 corresponding to performing the warm up programme five times a week for 5 weeks.

In week 1, participants reported to the test site with their own 5 iron club. Participants were instructed to place themselves in front of the tee when they were ready to

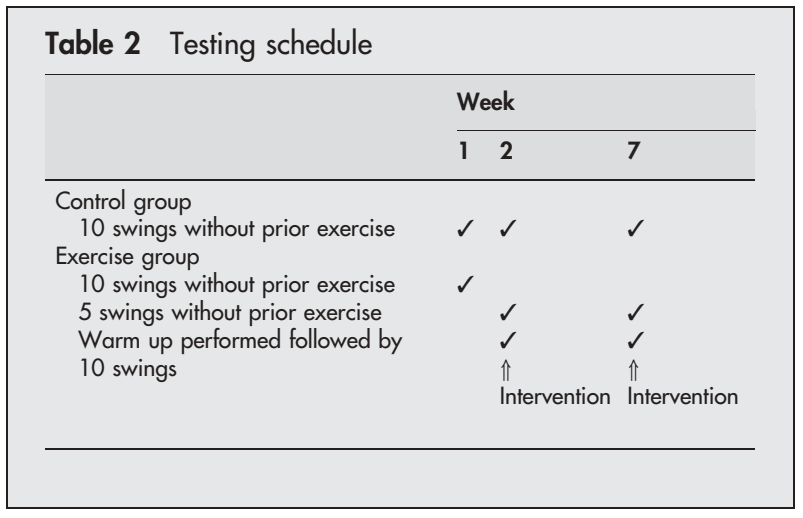

begin, and then to perform one air swing to ensure they were correctly lined up. When the golfers were ready to begin they were told that, "you have hit a great tee off shot, which has landed in the middle of the fairway. You have decided to use your 5 iron and are to hit as far and as accurately as possible, while maintaining your normal stroke". Participants then performed 10 swings to hit a real golf ball, with a 1 minute break between strokes.

In week 2, the control group underwent precisely the same procedure as in week 1 . The exercise group began by performing only five swings so that a measure of club head speed prior to warming up was obtained, which would then be compared with baseline values. The exercise group golfers were shown how to perform the warm up exercises, instructed with the same scenario as before and then performed their 10 swings. After completing the 10 swings, the exercise group were given a copy of the exercises and told that these were to be performed before golf play and practice, as well as at home, so that in total the exercises were performed five times a week for 5 weeks. The exercise group members were also asked to complete a diary record of their golfing activities including how often they performed the warm up each week.

In week 7, the control group again performed 10 swings without prior exercise, and the exercise group performed five swings without any prior exercise, then performed the warm up programme, and finally performed 10 swings. The five swings were compared with baseline levels to show the magnitude of improvement after performing the warm up programme for 5 weeks. The 10 swings were used to determine the magnitude of improvement in club head speed due to performing the warm up programme over time when compared with baseline levels.

\section{Data analysis}

All data was double entered into SPSS software and checked. Frequencies and basic descriptive statistics were generated for the golfers' mean club head speeds, frequency of play, handicap, and age. The repeated measures test was performed to determine whether there was a difference between the exercise and control groups' mean club head 
speeds, and to determine whether there was an interaction over time (that is, if there was a different relationship between mean club head speed and time in the groups).

\section{RESULTS}

Club head speeds were measured for each participant in the control group on three occasions over the 7 week period in weeks 1, 2, and 7. Fig 1 shows the mean of the control group's 10 swings in weeks 1,2 , and 7 . There was no evidence of fatigue or learning effects within this group over the 7 weeks. With the exception of participant 10, whose mean club head speeds varied by $1.7 \mathrm{~m} / \mathrm{s}$, the rest of the group hardly varied their mean club head speed on a week to week basis (range $0.3-0.8 \mathrm{~m} / \mathrm{s}$ ).

From the diaries, no golfer increased their frequency of play over the 5 weeks, and $80 \%$ of the golfers performed the warm up programme five times a week; the other golfers performed the warm up 4-5 times a week. Fig 2 shows the exercise group's mean club head speeds over the testing period.

Figure 2 shows that the exercise group's mean club head speed improved at each testing week. The five swings in week 2 obtained similar values to the week 1 baseline values, which is to be expected as no intervention had yet been introduced. After performing the warm up in week 2, each golfer improved their mean club head speed showing the immediate effects of the warm up programme. In week 7 , after performing the five swings with no warm up, the golfers' mean club head speed had improved upon their baseline speeds, but not to the extent that the speeds were faster than after performing the warm up in week 2. This suggests that there was a slight conditioning effect when performing the warm up programme.

In week 7 , the golfers also performed 10 swings after undertaking the warm up programme and again every golfer increased their mean club head speeds further. Fig 2 clearly shows that performing the warm up programme prior to play was better than not doing any prior exercise, but performing the warm up programme five times a week over a period of time produces the best results in improving club head speed.

Fig 3 shows the means of the two groups over the 7 week testing period, and indicated two trends. Firstly, the exercise group's mean club head speeds increased over the three different testing periods whereas the control group data did not. This suggests that the intervention of the warm up programme was responsible for the increased club head speeds obtained by the exercise group. This trend is further supported because each golfer in the exercise group was matched with a golfer in the control group; therefore, there were no age, sex, or handicap effects. Secondly, the exercise group data not only had a large increase between weeks 1 and 2 (suggesting that performing a warm up prior to play is beneficial), but another large increase was obtained between

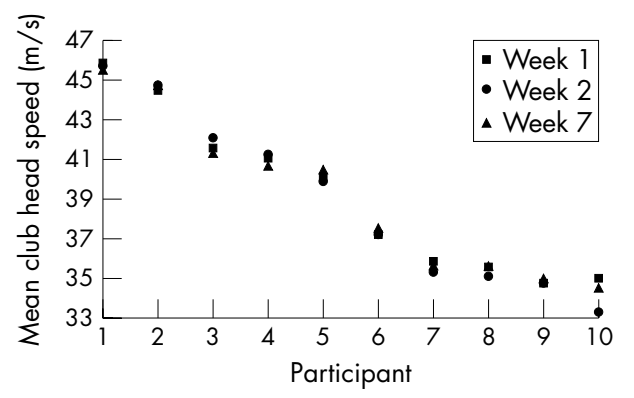

Figure 1 Control group mean club head speeds over testing period $(n=10)$.

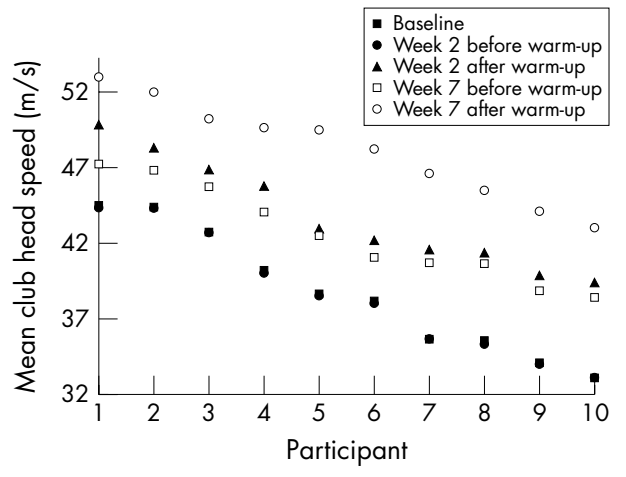

Figure 2 Exercise group mean club head speeds over testing period $(n=10)$.

weeks 2 and 7. The most likely explanation for this is that by performing the warm up programme 4-5 times a week for 5 weeks, performance is improved even more than just performing it immediately prior to play or practice.

A significant difference was found $(p=0.029)$ between the two groups. A significant interaction was also found between the groups over the 7 week testing period $(p<0.001)$.

\section{DISCUSSION}

To determine the immediate and short term effects of performing a warm up programme, 20 golfers were matched according to age ( \pm 2 years), gender, and handicap $( \pm 1)$. Ten of these golfers formed a control group, with the other 10 forming the exercise group. Between weeks 1 and 2, golfers in the exercise group improved their club head speed by $3-6 \mathrm{~m} / \mathrm{s}(12.8 \%)$ by performing the warm up immediately prior to their 10 strokes; this increased speed equates to a decreased handicap of approximately four shots. The suggested decrease in handicap can be calculated from a previous study that validated club head speed as a measure of performance. ${ }^{8}$ Between weeks 1 and 7 , golfers in the exercise group improved their club head speed by $7-10 \mathrm{~m} / \mathrm{s}(24.0 \%)$. This improvement occurred after performing the warm up programme prior to the 10 swings after having performed it 4-5 times a week for 5 weeks. This improvement equates to a decrease in handicap of approximately seven shots. These results show that by performing a warm up immediately prior to performance and over a period of time, golfers' club head speeds are likely to increase. The golfers in this study were not followed up after the last testing session was completed, so it is unknown whether their handicaps actually had decreased after the study.

As the golfers in this study were evenly matched for age, gender, and handicap, it is likely that the results obtained by the exercise group are due to the warm up programme rather

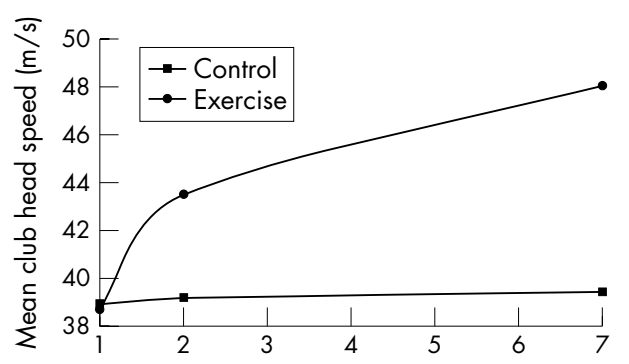

Figure 3 Overall mean club head speeds of exercise and control group participants in weeks 1,2 , and 7. 


\section{WHAT IS ALREADY KNOWN ON THIS TOPIC}

Very little was previously known on whether performing a golf specific warm up would improve golfing performance (measured by club head speed).

\section{WHAT THIS STUDY ADDS}

This study has shown that by warming up immediately prior to play, performance is significantly improved, and by performing it 4-5 times/week for 5 weeks, performance is even further improved.

than external factors. The results are further enhanced because the control group did not significantly improve their club head speed over the 7 week period. With the exception of one participant, the mean club head speeds of the control group did not vary more than $0.8 \mathrm{~m} / \mathrm{s}$ over the three testing periods. The outlying participant's mean club head speeds varied by approximately $1.7 \mathrm{~m} / \mathrm{s}$; however, this was not a progressive increase. The highest value was obtained in week 2 , rather than week 7 , suggesting that it could be an inconsistency in the participants' swing rather than a learning effect.

The five swings that were performed by the exercise group in week 7 were measured as having faster club head speeds than their initial baseline speeds. However, these speeds were not faster than those obtained after warming up. This suggests that performing the warm up, a conditioning programme over a 5 week period will increase golfers' baseline club head speeds, and means that a conditioning effect can occur and that golfers can improve their club head speed even more than by just performing a warm up immediately prior to play or practice. As the lowest handicap in this study was 12, it is possible that the improvement would not be as large with lower handicap golfers.

The warm up routine developed for this study only aimed at improving the golfers' long game. It needs to be determined whether a golfer's short game can also be improved with this warm up procedure. Unfortunately, we were unable to measure accuracy using this study design, so although the increases in club head speed correlated with decreased handicaps, this was without accuracy measures that may play a part in ultimately decreasing handicaps. Finally, it is unknown how long the effects of the warm up last, and thus this should be investigated further.

\section{CONCLUSION}

While practice is essential for perfecting the golf swing, data from this study suggests that sport specific conditioning is also valuable. Present findings indicate that a golf specific conditioning programme undertaken $4-5$ times a week for 5 weeks using the protocol outlined was associated with significant improvements in club head speed in this group of golfers. As yet, there has been no evaluation concerning the benefits of a warm up with regards to injury prevention, which is the next logical step following on from this study.

\section{ACKNOWLEDGEMENTS}

A Fradkin undertook the above work as part fulfilment of her Master of Applied Science degree, under the supervision of Dr C Sherman at the School of Health Sciences, Deakin University. We thank Dr P Le Rossignol and Dr E Bradshaw for the advice on the experimental arrangement.

\section{Authors' affiliations}

A J Fradkin, Monash University

C A Sherman, Deakin University

C F Finch, University of New South Wales

Conflict of interest: none declared

\section{REFERENCES}

1 Hedrick A. Physiological responses to warm-up. J Strength Cond Res 1992;14:25-7.

2 Bourne G. Thephysiological basis of the warm-up. Mod Athlete Coach 1992;30:36-38.

3 Blank LB. Effects of warm-up on speed. Athletic J 1955;35:10.

4 Carlile F. Effect of preliminary passive warming on swimming durations upon some physiological variables during an exercise corresponding to the WC170. Eur J Physiol 1980;43:93-100.

5 DeVries HA. Evaluation of static stretching procedures for improvement of flexibility. Res Q Exerc Sport 1962;33:222-9.

6 Phillips WH. Influence of fatiguing warm-up exercises on speed of movement and reaction latency. Res Q Exerc Sport 1963;34:370-8.

7 Roca J. Effects of warming-up on reaction time and movement in the lower extremities. J Sports Med 1979:165-71.

8 Fradkin A. Effects of a warm-up program on club head speed in male golfers. Masters thesis. Melbourne, Australia: Deakin University, School of Health Sciences, 2002.

9 De Vries HA. Effects of various warm-up procedures on 100-yard times of competitive swimmers. Res Q Exerc Sport 1959;30:11-20.

10 Theriault G, Lachance P. Golf injuries-an overview. Sports Med 1998;26:43-57.

11 Sherman CA, Finch CF. Preventing injuries to competitive and recreational adult golfers: what is the evidence. J Sci Med Sport 2000;3:65-78.

12 Hetu FE, Christie CA, Faigenbaum AD. Effects of conditioning on physical fitness and club head speed in mature golfers. Percept Mot Skills 1998;86:811-15

13 Westcott WL, Parziale JR. Golf Power. Fitness Manage 1997:39-41.

14 Jones $\mathbf{D}$. The effects of age on performance of professional golfers. In: Cochran AJ, ed. Science and golf: Proceedings of the Scientific Congress of Golf, Scotland. 1998:46-50.

15 Lennon HM. Physiological profiling and physical conditioning for elite golfers. In: Cochran AJ, ed. Science and golf: Proceedings of the Scientific Congress of Golf, Scotland. 1998:58-64.

16 Mallon WJ, Hawkins RJ. Injuries in golf. In: Renstrom PAFH, ed. Clinical practice of sports injury prevention and care. Oxford: Blackwell Scientific Publications, 1994:495-506.

17 Brendecke P. Golf injuries. Sports Med Digest 1990;12:1-2.

18 Theriault G, Lachance P. Golf injuries-an overview. Sports Med 1998;26:43-57.

19 Maldozzo GFJ. An anatomical and biomechanical analysis of the full swing. J Strength Cond Res 1986;9:6-8, 77-9.

20 Buchan JF. Golf injuries: treatment and prevention. In: Payne SDW, ed. Medicine, sport and the law. Oxford: Blackwell Scientific Publications, 1990:354-9.

21 Jobe FW, Schwab DM. Golf for the mature athlete. Clin Sports Med $1991 ; 10: 269-82$

22 Galanty HL, Puffer JC. Golf. In: Mellion MB, ed. Sports medicine secrets. Philadelphia: Hanley \& Belfus Inc, 1994:390-5.

23 McCarroll JR. Golf. In: Fu FH, Stone DA, eds. Sports injuries: mechanisms, prevention, treatment. Maryland: Williams \& Wilkins, Baltimore, 1994:375-81.

24 Adlington GA. Proper swing techniques and biomechanics of golf. Clin Sports Med 1996;15:9-26.

25 Halle J. Fitness tips for golf. Physician Sports Med 1996;23:87.

26 Hosea TM, Gatt CJ. Back pain in golf. Clin Sports Med 1996; 15:37-53.

27 Pink MM, Jobe FW, Yocum LA, et al. Preventative exercises in golf-arm, leg, and back. Clin Sports Med 1996;15:147-62.

28 Stover C, Stoltz J. Golf for the senior player. Clin Sports Med 1996; 15:163-79.

29 Belcher JR, Jobe FW, Pink MM. Electromyographic analysis of the hip and knee during the golf swing. Clin J Sports Med 1995;5:162-6.

30 Hosea TM, Gatt CJ, Galli KM, et al. Biomechanical analysis of the golfer's back. In: Cochran AJ, ed. Science and golf: Proceedings of the Scientific Congress of Golf, Scotland. 1990:43-8.

31 Jobe FW, Moynes DR, Antonelli DJ. Rotator cuff function during golf swing. Am J Sports Med 1986;14:388-92.

32 Jobe FW, Schwab DM. Golf for the mature athlete. Clin Sports Med $1991 ; 10: 269-2$.

33 McCarroll JR. Golf. In: Fu FH, Stone DA, eds. Sports injuries: mechanisms, prevention, treatment. Baltimore, Maryland: Williams \& Wilkins, 1994:375-81.

34 Pink MM, Jobe FW, Perry J. Electromyographic analysis of the shoulder during the golf swing. Int J Sports Biomech 1985;1:221-32.

35 Pink MM, Perry J, Jobe FW. Electromyograpic analysis of the trunk in golfers. Am J Sports Med 1993;21:385-8.

36 Slater-Hammel AT. Action current study of contraction movement relationships in the golf stroke. Res Q Exerc Sport 1948;19:164-77. 